\title{
Evaluation of the biocompatibility of resin-based root canal sealers in rat periapical tissue
}

\author{
Noriko MUTOH, Takenori SATOH, Hirotaka WATABE and Nobuyuki TANI-ISHII \\ Department of Oral Medicine, Division of Endodontics, Kanagawa Dental University, 82 Inaoka-cho, Yokosuka 238-8580, Japan \\ Corresponding author, Nobuyuki TANI-ISHII; E-mail: nobu0337@kdcnet.ac.jp
}

\begin{abstract}
We evaluated the biocompatibility of resin-based root canal sealers (RCSs) in the periapical tissues of rats. Wistar rats underwent tooth replantation for reproducing the response of periapical tissue with RCSs. The resin-based Epipany SE ${ }^{\mathrm{TM}}$, AH Plus Jet ${ }^{\mathrm{TM}}$, the eugenol-based sealer (Canals) and a control group were employed. The upper right first molar was extracted and applied with RCSs on apices, and then the tooth was repositioned. Histological evaluation demonstrated that mild inflammation occurred in the periapical tissue with Epiphany and AH Plus Jet sealers on day 7, whereas Canals induced severe-to-moderate inflammation. The statistical analyses demonstrated that the significant differences were observed between Canals and the other groups on day 7 regarding inflammatory response. On day 14, the lesions induced by all sealers were healed and replaced predominantly by fibrous connective tissue. Our results suggest that Epiphany SE and AH Plus Jet are good biocompatible materials.
\end{abstract}

Keywords: Biocompatibility, Endodontic sealer, Tooth replantation, Periapical tissue response

\section{INTRODUCTION}

Biocompatibility is an important factor as well as physical and chemical features for selecting materials for endodontic therapy because of the direct contact of materials with periapical tissue ${ }^{1}$. Root canal sealers (RCSs) may be extruded through the apical foramen. Hence, they may remain in the periapical tissue for a prolonged period, thereby making the biocompatibility of RCSs an important factor in healing ${ }^{2,3}$.

Resin-based RCSs such as Epiphany $\mathrm{SE}^{\mathrm{TM}}$ or $\mathrm{AH}$ Plus Jet ${ }^{\mathrm{TM}}$ have been introduced to replace conventional eugenol-based sealers under the premise of improving clinical performance and eliciting satisfactory tissue reactions ${ }^{4-7)}$. The biocompatibility of methacrylate resinbased Epiphany SE and epoxy resin-based AH Plus Jet has been evaluated. First-generation Epiphany was shown to induce bone formation and cause a slight osseous inflammatory reaction in the in vivo experiment ${ }^{8)}$. The in vitro experiments demonstrated that Epiphany in freshly mixed or set conditions showed severe-to-moderate cytotoxicity ${ }^{9}$, and its cytotoxicity increased with time, posing significant risks ${ }^{10,11)}$. The other in vitro studies tested the effect of Epiphany on human fibroblasts and L929 cells, and showed its strong cytotoxicity on these cells ${ }^{12,13)}$. However, Epiphany showed no genotoxic potential upon human leukocytes, although it induced apoptosis in $>90 \%$ of cells ${ }^{12}$. The in vitro study by Baraba et al. showed no genotoxic potential for Epiphany on human leukocytes ${ }^{14)}$. However, the in vivo experiments regarding Epiphany SE, the latest generation of metacrylate resin-based sealers, have not been thoroughly conducted.

Color figures can be viewed in the online issue, which is available at J-STAGE.

Received Aug 15, 2012: Accepted Feb 7, 2013

doi:10.4012/dmj.2012-218 JOI JST.JSTAGE/dmj/2012-218
Numerous in vitro studies have been carried out on the biocompatibility of AH Plus. Some studies ${ }^{15,16)}$ reported that its cytotoxicity was not appreciable, whereas other studies ${ }^{17)}$ demonstrated cytotoxicity and genotoxicity: AH Plus Jet was shown to exhibit severe toxicity until $96 \mathrm{~h}$, and subsequently toxicity decreased gradually over 1 week. AI-Hiyasat et al. showed that $\mathrm{AH}$ Plus was the most biocompatible material in mouse fibroblasts for $48 \mathrm{~h}$ according to the MTT assay ([3-4,5-Dimethylthiazol-2-yl]-2,5-diphenyltetrazolium bromide) ${ }^{18)}$. Furthermore, the intraosseous implantation of endodontic materials into the tibia $^{8}$ and the application of RCSs have been carried out on large animals such as $\operatorname{dogs}^{19,20)}$. These in vivo studies demonstrated that $\mathrm{AH}$ Plus has a biologic potential.

Epiphany has been shown to induce satisfactory tissue reactions ${ }^{21}$, whereas AH Plus elicits severe tissue responses in the in vivo experiment ${ }^{22}$. Both of these RCSs have been approved for endodontic use by the US FDA (Food and Drug Administration). However, there are few in vivo studies evaluating their biocompatibility in the periapical tissue. Thus, we aimed to evaluate the effects of the extrusion of resin-based RCSs such as Epiphany $\mathrm{SE}$ and AH Plus Jet and their biocompatibility in the periapical tissue using a recently established animal model for tooth replantation ${ }^{23)}$.

\section{MATERIALS AND METHODS}

\section{Animal experiments}

All animal procedures conformed to the protocols reviewed and approved by the Ethics in Animal Research Committee of Kanagawa Dental University (Yokosuka, Japan). These procedures complied with the International Guiding Principles for Biomedical 
Table 1 Composition of the sealers and their manufactures

\begin{tabular}{ccc}
\hline Sealers & Materials & Composion \\
Epiphany SE & Metacrylate resine & $\begin{array}{c}\text { HEMA, Bis-GMA, Calcium phosphate, 2,2-Bis(4-metacryloxypolyethovyphenyl) } \\
\text { propane, Barium borosilicate glass, Bismuth oxychloride, Silica, Allyl thiourea, } \\
\text { Benzoyl peroxide, Photo-initiator, Stabilizers and pigment }\end{array}$ \\
AH Plus Jet & Epoxy resine & $\begin{array}{r}\text { Bisphenol-A and -F epoxy resins, Calcium tungstate, Zirconia oxide, } \\
\text { Silica, Iron oxide pigment, Amines, Silicone oil }\end{array}$ \\
Canals & Zinc Oxide Eugenol & ZnO, Rosine, Bismuth subcarbonate, Barium sulfate Eugenol, Penuts oil \\
\hline
\end{tabular}

Research Involving Animals (Geneva, 1985).

Forty female Wistar rats (4 weeks old; weights are less than $90 \mathrm{~g}$ ) were used. Thirty rats were used for the experimental group of Epiphany SE (Pentron Clinical Technologies, Wallingford, CT, USA), AH Plus Jet (Dentsply/Detrey, Konstanz, Germany) and Canals (Showa Yakuhin Kako, Tokyo, Japan). The composition of the three RCSs is demonstrated in Table 1. Ten rats were used as the control group. Under anesthesia (chloral hydrate $350 \mathrm{mg} / \mathrm{kg}$, i.p.), the upper right first molar (M1) was extracted with a pair of Howe pliers (YDM Company Limited, Tokyo, Japan) or forceps with hooks. We used only upper right molars to keep the influence of occlusal trauma to a minimum, since the occlusal trauma elicits the pathological healing patterns in the pulp cavity of the replanted tooth ${ }^{24}$. Bleeding from the M1 alveolar socket was inhibited with a sterilized paper point (Pierce Company Limited, Tokyo, Japan). We used Epiphany SE, AH Plus Jet, and Canals according to manufacturer instructions. Ten microliters of these mixed materials were applied to each of the five root apices of M1 (Fig. 1) using a 27-G needle (Terumo Company Limited, Tokyo, Japan) attached to a $1-\mathrm{mL}$ plastic syringe ${ }^{23)}$. The extracted tooth with materials was immediately repositioned in the original socket after the confirmation of hemostasis; these were classified as the "experimental groups". The replanted tooth did not undergo further treatments according to the method of a previous report $\mathrm{t}^{25,26)}$.

\section{Tissue preparation}

Samples were collected from 5 rats in each group and stage at intervals of 7 and 14 days after tooth replantation (5 samples in each $\times 2$ periods $\times 4$ groups $=40$ samples). At each stage, rats were anesthetized and perfused via the transcardial route with physiological saline followed by $4 \%$ paraformaldehyde in $0.1 \mathrm{M}$ phosphate buffer $(\mathrm{pH}$ 7.4). Maxillae were removed en block and immersed in the same fixative for an additional $12 \mathrm{~h}$. After decalcification in a $4 \%$ solution of ethylenediamine tetraacetic acid disodium salt for 4 weeks at $4^{\circ} \mathrm{C}$, the samples were embedded in paraffin. Specimens for histological analyses were cut in the sagittal plane at a thickness of $5 \mu \mathrm{m}$, and the sections were stained with hematoxylin and eosin (H\&E).

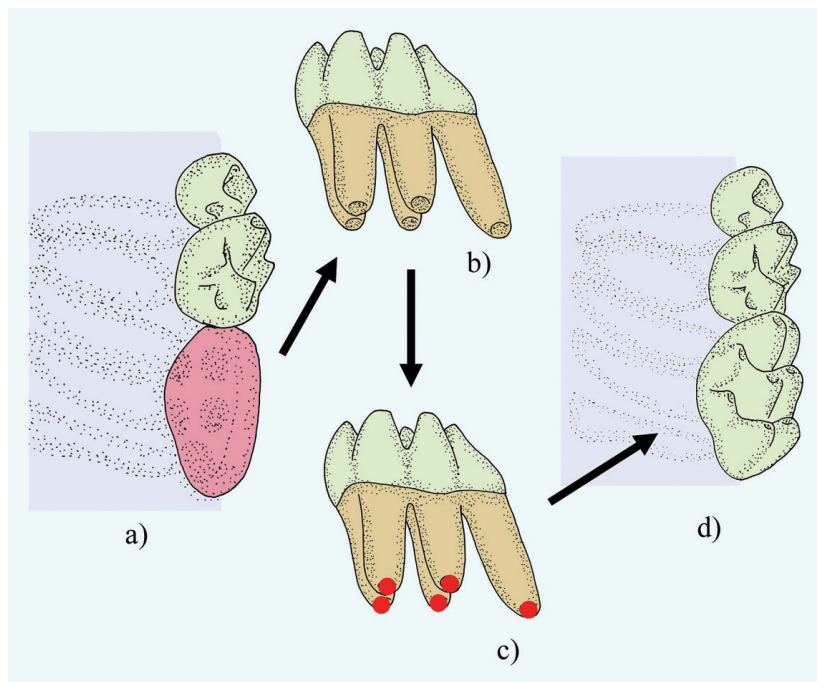

Fig. 1 Animal model for tooth replantation to evaluate the biocompatibility of endodontic sealers.

(a) The alveolar socket of the upper right first molar (M1). (b) M1 possesses five roots. (c) Ten microliters of the mixed material are applied to each of the five root apices of M1. (d) Extracted M1 is repositioned in the original socket after hemostasis has been confirmed.

\section{Histomorphological parameters}

The histomorphological parameters used in this study were based upon previously described criteria ${ }^{23,25,26)}$. For the determination of scores, sections were evaluated according to four parameters. The first parameter was inflammatory reactions: 0 , none or few inflammatory cells and no reaction; 1, <25 inflammatory cells and a mild reaction; 2, 25-125 inflammatory cells and a moderate reaction; $3,>125$ inflammatory cells and a severe reaction. Quantitative evaluations were done in the micrographs taken from ten areas of sections at $\times 400$ magnification. The second parameter was cementum resorption: absent or present. The third parameter was dentin resorption: absent or present. The final parameter was the thickness of the periodontal ligament at the apical region: 0 , normal; 1, slightly increased; 
2, moderately increased; 3, severely increased. The observer was blinded to the treatment allocation. We selected the most appropriate section (one section form each sample), where the apical foramen is most widely open to the periodontal ligament, from each sample for the histomorphological analysis.

\section{Statistical analyses}

Statistical analyses of the histopathological parameters described above were carried out with a Bonferroni's test (one-way analysis of variance; ANOVA) using statistical software (SPSS 16.0J for Windows; SPSS Japan, Tokyo, Japan). $P<0.05$ was considered significant.

\section{RESULTS}

Histological findings are demonstrated in Table 2. The control group showed a slight inflammatory response (mild was 20\%), no resorption of dentin, little resorption of cementum (20\%), and a moderate increase in the periodontal ligament space on day 7; subsequently, no inflammatory response, little resorption of dentin (20\%), little resorption of cementum (20\%), and little increase (slight increase was 20\%) in the periodontal space were observed on day 14. The Epiphany SE group showed a slight inflammatory response (mild was 20\%), no resorption of dentin, little resorption of cementum (20\%), and a moderate increase in the periodontal ligament space on day 7; subsequently, no inflammatory response, little resorption of dentin (20\%), little resorption of cementum (20\%), and a slight increase (slight increase was $80 \%$; moderate increase was 20\%) in the periodontal space were seen on day 14. The AH Plus Jet group showed a slight inflammatory response (mild was $20 \%$, little resorption of dentin (20\%), little resorption of cementum (20\%), and a moderate increase in the periodontal ligament space on day 7; subsequently, a slight inflammatory response, little resorption of dentin (20\%), little resorption of cementum $(20 \%)$, and a slight increase (slight increase was $80 \%$; moderate increase was $20 \%$ ) in the periodontal space were observed on day 14. The Canals group showed a moderate inflammatory response (moderate was $80 \%$; severe was $20 \%$ ), little resorption of dentin (20\%), little resorption of cementum (20\%), and a severe increase in the periodontal ligament space on day 7; subsequently, a slight inflammatory response (mild was

Table 2 Histopathologic findings in each experimental group

\begin{tabular}{|c|c|c|c|c|c|c|c|c|}
\hline \multirow[b]{2}{*}{ Finding } & \multicolumn{4}{|c|}{ Day 7} & \multicolumn{4}{|c|}{ Day 14} \\
\hline & Control & $\begin{array}{l}\text { Epiphany } \\
\text { SE }\end{array}$ & $\begin{array}{l}\text { AH Plus } \\
\text { Jet }\end{array}$ & Canals & Control & $\begin{array}{l}\text { Epiphany } \\
\text { SE }\end{array}$ & $\begin{array}{c}\text { AH Plus } \\
\text { Jet }\end{array}$ & Canals \\
\hline
\end{tabular}

Inflammatory response in periapical tissue $(n=5)$

Absent (n)

Mild (n)

Moderate $(n)$

Severe $(n)$

Dentin resorption $(n=5)$

Absent (n)

Present $(n)$

Cementum resorption $(n=5)$

Absent (n)

Present $(n)$

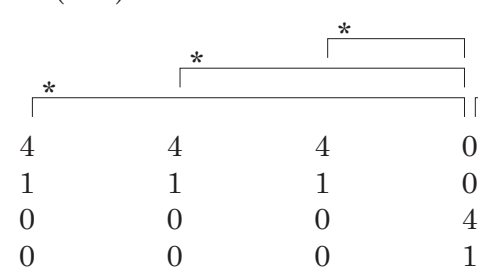

5

0

5

0

4
1

1

4
1

\section{4}

1

$1 \quad 1$

$*$
0
0
4
1

5
0
0
0

$\begin{array}{lll}5 & 4 & 4 \\ 0 & 1 & 1 \\ 0 & 0 & 0 \\ 0 & 0 & 0\end{array}$

Apical periodontal ligament space $(n=10)$

(apical to bone surface)

Normal ( $n$ )

Slightly increased $(n)$

Moderately increased $(n)$

Severely increased $(n)$

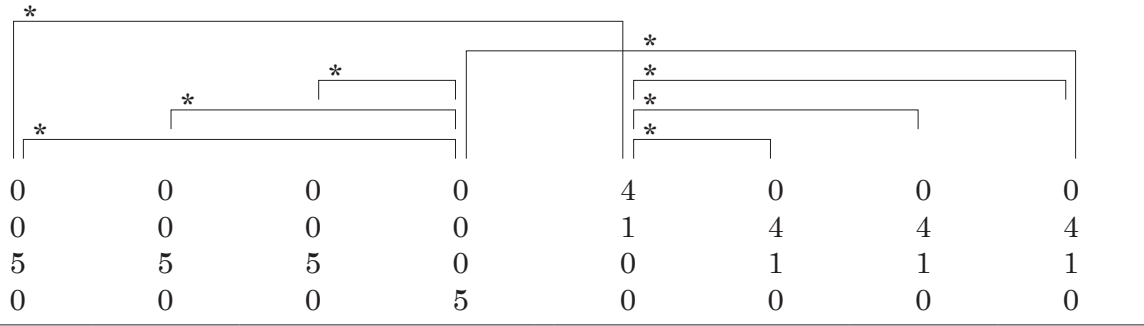

${ }^{*} p<0.05$ 
$20 \%$ ), little resorption of dentin (20\%), little resorption of cementum (20\%), and a slight increase (slight increase was $80 \%$; moderate increase was $20 \%$ ) in the periodontal space were seen on day 14 . The statistical analyses demonstrated that the significant differences were observed between Canals and the other groups on day 7 regarding inflammatory response in periapical tissue and apical periodontal space. All experimental groups showed significant differences compared with control group regarding apical periodontal space on day 14 .

\section{Epiphany SE}

On day 7, no or mild infiltration of inflammatory cells were observed in dense fibrous tissues with numerous blood vessels (Fig. 2a). By day 14, inflammatory cells almost disappeared and the periapical tissue recovered, showing normal periodontal tissue (Fig. 2b).

\section{AH Plus Jet}

On day 7, no or mild infiltration of inflammatory cells was observed in dense fibrous tissues with numerous
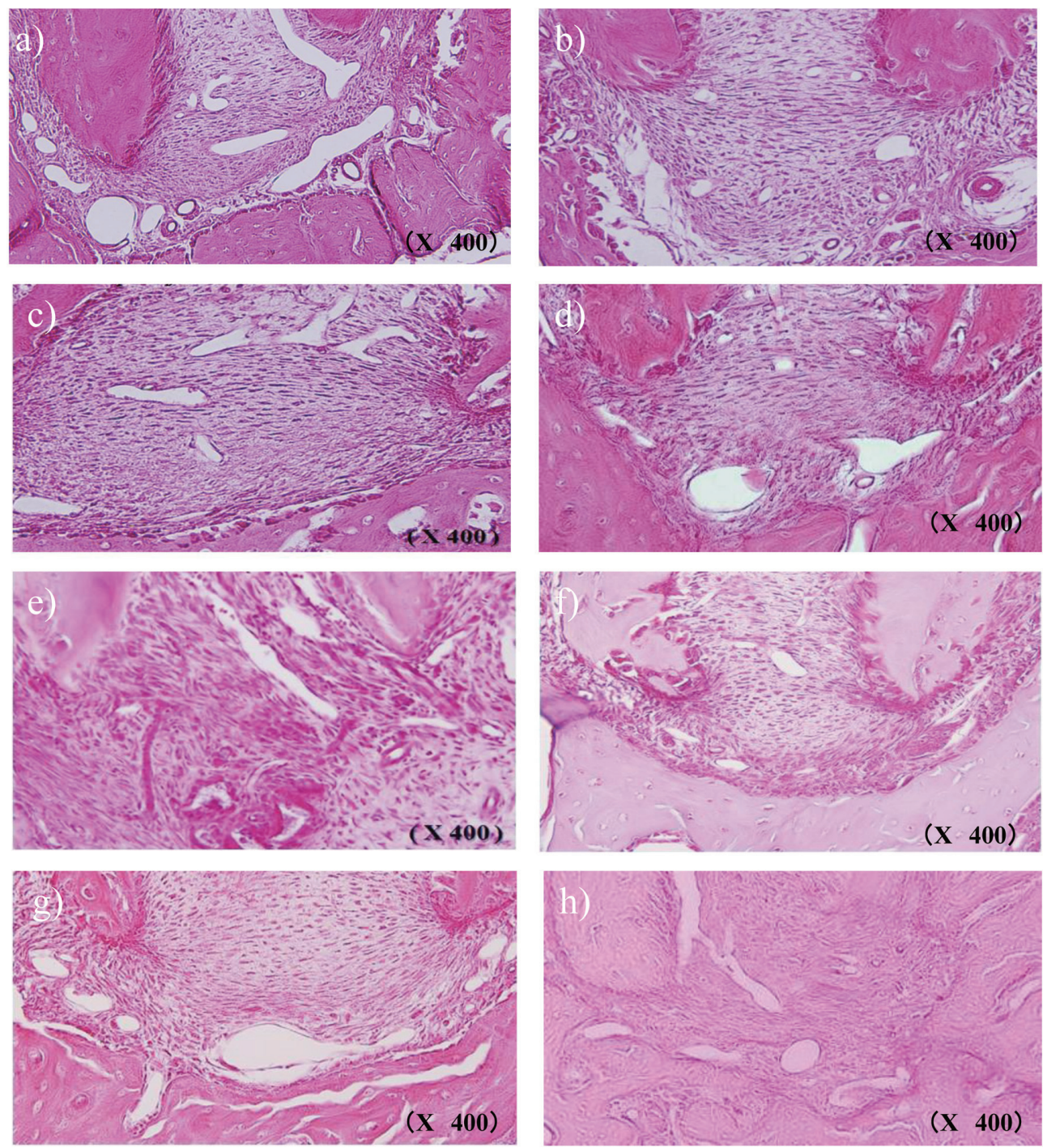

Fig. 2 Histological images.

(a) Epiphany SE on day 7. Mild infiltration of inflammatory cells. (b) Epiphany SE on day 14. Numerous fibrous tissues and the formation of blood vessels. (c) AH Plus Jet on day 7. Mild infiltration of inflammatory cells. (d) AH Plus Jet on day 14. Numerous fibrous tissues and the formation of blood vessels. (e) Canals on day 7. Moderate infiltration of inflammatory cells (PMNs, macrophages and lymphocytes) are observed in the numerous fibrous tissue. (f) Canals on day 14. Numerous fibrous tissues and the formation of blood vessels. (g) Control on day 7. Slight infiltration of inflammatory cells in the fibrous tissue. (h) Control on day 14. Numerous fibrous tissue and the formation of blood vessels. 


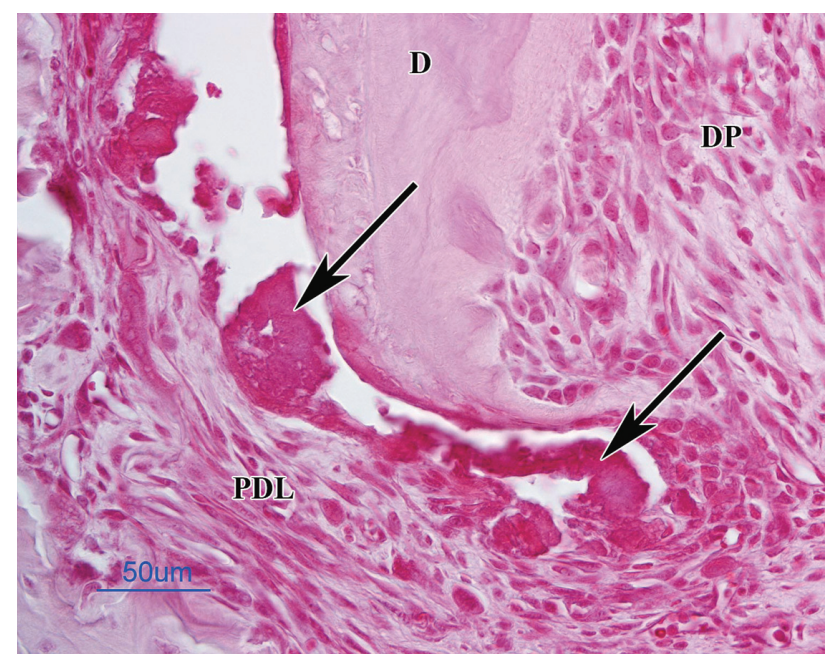

Fig. 3 H\&E stained section in the Canals group on day 7. Amorphous materials (arrows) are recognized in the periodontal ligament (PDL). D: dentin, DP: dental pulp.

blood vessels (Fig. 2c). By day 14, inflammatory cells almost disappeared and the periapical tissue recovered, showing normal periodontal tissue (Fig. 2d).

\section{Canals}

On day 7, moderate infiltration of inflammatory cells (PMNs, macrophages, and lymphocytes) was observed in dense fibrous tissues with numerous blood vessels (Fig. 2e). Amorphous materials were recognizable in the periodontal ligament (Fig. 3). By day 14, inflammatory cells disappeared, and the periapical tissue showed normal periodontal tissue (Fig. 2f).

\section{Control}

On day 7, no or mild infiltration of inflammatory cells was observed in fibrous tissue with numerous blood vessels (Fig. 2g). On day 14, periapical tissue showed normal periodontal tissue (Fig. 2h).

\section{DISCUSSION}

We clearly demonstrated the biocompatibility of Epiphany SE and AH Plus Jet by analyzing the response of periapical tissue to RCSs using tooth replantation. The establishment of the in vivo animal model is considerably important for precisely evaluating the biocompatibility of RCSs. Our recently established animal model using small animals such as rats has several advantages compared with the previous animal model using big animals such as dogs. First, the systematic analyses are feasible due to the use of many samples and the minimum of an individual difference. Second, the moisture contamination of the apical area can be controlled appropriately and the responses of the periapical tissue can be evaluated quantitatively by histological observation, since the procedure of tooth replantation enables the root apices with endodontic materials to be sequestered immediately after its reposition. In contrast, the unset materials such as slow-setting sealers implanted into a freshly prepared bone cavity are susceptible to be partially displaced by tissue fluids ${ }^{27)}$, although intraosseous models have been used as an appropriate environment for in vivo testing of endodontic material ${ }^{26,28-30)}$. Third, our model mimics the clinical situation that the extrusion of RCSs contacts with the periapical tissue through the apical foramen. Our system could assess the biocompatibility of RCSs in the periapical tissue, although the procedure of the application of RCSs is different from the clinical procedure to remove pulp tissue before applying the endodontic materials.

Another important point is to evaluate the effect of surgery itself on tissue responses. The histological analysis of the tissue reaction in the control group showed that the surgical trauma caused by tooth replantation itself induces a slight inflammation on day 7 , and subsequently an inflammatory reaction disappear until day 14, although dentin resorption, cementum resorption, and/or increased apical periodontal ligament space may be observed on day 14 . Thus, the comparison between the control and experimental groups is essential to analyze the histomorphological parameters for the precise evaluation of tissue responses, although parametric tests are inadequate for the evaluation of scores.

There are no data on the histological analyses of periapical tissue responses to endodontic materials except for the use of large animals such as dogs in which the periapical tissue responses to materials could be assessed after preparation of the root canal. Our experimental animal model showed precisely the effect of RCSs on the periapical tissue. The zinc oxideeugenol (ZOE)-based sealer Canals was used as a positive control in the present study, showing severe-tomoderate inflammation with the significant difference demonstrated by the score of inflammatory reactions. Since it is classified as a "slow-setting material", the unset material implanted into the periapical tissue would probably have been partially dispersed by tissue fluid until 7 days after application. Actually, amorphous materials remained in the periapical lesions in this study (Fig. 3). Thus, our animal model simulated the periapical tissue response to the ZOE sealer which overflows from the root apex before obturation of the root canal. Regardless of the presence of ZOE components, the inflammatory reaction was recognized during the early stages after the procedure because of the surgical trauma mentioned above. Good biocompatibility was shown in the periapical tissue reaction to the RCSs.

In the present study, neither resin-based RCSs demonstrated a severe inflammatory reaction compared with the reactions of the positive control Canals 7 days after application. When using Epiphany SE and AH Plus Jet, the periapical area was filled with well-organized granulation tissue with numerous fibroblasts and blood vessels. A moderately increased periodontal ligament 
space from the root apices to the bone surface was also observed in the control on day 7. Good biocompatibility was shown in the periapical tissue reaction to both resinbased RCSs which were set by day 14 . Few authors have investigated the cytotoxicity of the self-adhesive RCSs such as Epiphany SE and AH Plus Jet. Ames et al. has demonstrated that Real Seal SE, a self-adhesive sealer that is compositionally similar to Epiphany SE, is less toxic than Real Seal ${ }^{31}$. The cyto-compatibility of self-adhesive (without a separate priming step) methacrylate resin-based sealers may be comparable or better than those of previous generation non-etching resin sealers. The recent advancement of bonding technology may be the development to reduce leakage and infection. The first generation of Epiphany showed highly cytotoxic effects ${ }^{9,10)}$ and induced inflammatory reactions ${ }^{21}$. Furthermore, the Epiphany and Resilon systems induced a slight inflammatory reaction after 42 days. The toxicity of Epiphany might be explained by the presence of unpolymerized hydrophilic monomers that can readily diffuse into the cell culture medium ${ }^{32)}$ and elicit a significant toxicity ${ }^{33)}$. The second generation of Epiphany (Epiphany SE) is a non-etching methacrylate with an acidic resin monomer that is originally found in primers that have been incorporated into self-adhesive resin-based sealers ${ }^{34)}$. The Epiphany $\mathrm{SE}$ is the latest generation of metacrylate resin-based sealers, and one of its components is HEMA, which is known to be cytoxic even at low concentrations ${ }^{35}$. In this experiment, the Epiphany SE group showed a moderate inflammation on day 7, although it showed little inflammation on day 14 . Epiphany SE has been shown to have cytotoxic efforts immediately after mixing, which toxicity decreased gradually over 1 week. AH Plus and AH Plus Jet also have highly cytotoxic effects ${ }^{15,16,36}$. The cytotoxicity of AH Plus is thought to arise from the release of bisphenol $\mathrm{A}$; bisphenol A has been identified as a mutagenic component of materials, and might also be cytotoxic ${ }^{37}$. The release of minute amounts of formaldehyde from $\mathrm{AH}$ Plus may contribute to cytotoxicity in the early phase of setting sealers ${ }^{38}$. AH Plus has been shown to have highly cytotoxic effects immediately after mixing as well as after 24 and $48 \mathrm{~h}$ setting periods in contact with cells, and subsequently the toxicity decreased gradually over 1 week $^{17,18)}$. Our histological findings revealed that Epiphany SE and AH Plus Jet are good biocompatible materials with respect to tissue responses in rat periapical tissues. These resin-based RCSs exhibited similar patterns of infiltration of inflammatory cells compared with the control group after long experimental periods.

In conclusion, the findings in the present study support the favorable clinical results observed using resin-based RCSs. The experimental animal model that we used to evaluate the response of periapical tissue to endodontic materials was not entirely comparable with the response elicited by human tissue. Under carefully standardized conditions, this model could be used to simulate the inflammatory process induced by iatrogenic means during obturation of the root canal in humans, and could therefore be an effective tool to study several aspects of the periapical tissue reaction. The results showed that the tested Epiphany SE and AH Plus Jet sealers induced a mild inflammatory response in the periapical tissue. Those RCSs could possess better tissue compatibility compared with eugenol sealers.

\section{REFERENCES}

1) Torabinejad M, Walton RE. Endodontics: principles and practice, 4th ed. Saunders Elsevier; 2009. p. 1-474.

2) Willershausen B, Marroquín BB, Schäfer D, Schulze R. Cytotoxicity of root canal filling materials to three different human cell lines. J Endod 2000; 26: 703-707.

3) Huang FM, Tai KW, Chou MY, Chang YC. Cytotoxicity of resin-, zinc oxide-, eugenol-, and calcium hydroxide-based root canal sealers on human periodontal ligament cells and permanent V79 cells. Int Endod J 2002; 35: 153-158.

4) Ørstavik D. Materials used for root canal obturation: technical, biological and clinical testing. Endod Topics 2005; 12: $25-38$.

5) Sousa-Neto MD, Coelho FI, Marchesan MA, Alfredo E, SilvaSousa YTC. Ex vivo study of the adhesion of an epoxy-based sealer to human dentine submitted to irradiation with Er: YAG and Nd: YAG. Int Endod J 2005; 38: 866-870.

6) Versiani MA, Carvalho-Junior JR, Padilha MI, Lacey S, Pascon EA, Sousa-Neto MD. A comparative study of physicochemical properties of AH Plus and Epiphany root canal sealants. Int Endod J 2006; 39: 464-471.

7) Bouillaguet S, Shaw L, Barthelemy J, Krejci I, Wataha JC. Long-term sealing ability of Pulp Canal Sealer, AH Plus, GuttaFlow and Epiphany. Int Endod J 2008; 41: 219-226.

8) Sousa CJ, Montes CR, Pascon EA, Loyola AM, Versiani MA. Comparison of the intraosseous biocompatibility of AH Plus, EndoREZ, and Epiphany root canal sealers. J Endod 2006; 32: 656-662.

9) Lodiene G, Morisbak E, Bruzell E, Ørstavik D. Toxicity evaluation of root canal sealers in vitro. Int Endod J 2008; 41: 72-77.

10) Bouillaguet S, Wataha JC, Tay FR, Brackett MG, Lockwood $P E$. Initial in vitro biological response to contemporary endodontic sealers. J Endod 2006; 32: 989-992.

11) Heitman EP, Joyce AP, McPherson JC, Roberts S, Chuang A. An in vitro evaluation of the growth of human periodontal ligament fibroblasts after exposure to a methacrylate-based endodontic sealer. J Endod 2008; 34: 186-189.

12) Eldeniz AU, Mustafa K, Ørstavik D, Dahl JE. Cytotoxicity of new resin-, calcium hydroxide- and silicone-based root canal sealers on fibroblasts derived from human gingiva and L929 cell lines. Int Endod J 2007; 40: 329-337.

13) Karapınar-Kazandağ M, Bayrak OF, Yalvaç ME, Ersev H, Tanalp J, Sahin F, Bayirli G. Cytotoxicity of 5 endodontic sealers on L929 cell line and human dental pulp cells. Int Endod J 2011; 44: 626-634.

14) Baraba A, Zelježić D, Kopjar N, Mladinić M, Anić I, Miletić I. Evaluation of cytotoxic and genotoxic effects of two resinbased root-canal sealers and their components on human leucocytes in vitro. Int Endod J 2011; 44: 652-661.

15) Koulaouzidou EA, Papazisis KT, Beltes P, Geromichalos GD, Kortsaris AH. Cytotoxicity of three resin-based root canal sealers: an in vitro evaluation. Endod Dent Traumatol 1998; 14: $182-185$.

16) Tai KW, Huang FM, Chang YC. Cytotoxic evaluation of root canal filling materials on primary human oral fibroblast cultures and a permanent hamster cell line. J Endod 2001; 27: 571-573.

17) Huang TH, Yang JJ, Li H, Kao CT. The biocompatibility evaluation of epoxy resin-based root canal sealers in vitro. 
Biomaterials 2002; 23: 77-83.

18) Al-Hiyasat AS, Tayyar M, Darmani H. Cytotoxicity evaluation of various resin based root canal sealers. Int Endod J 2010; 43: 148-153.

19) Tanomaru Filho M, Leonardo MR, Silva LA, Utrilla LS. Effect of different root canal sealers on periapical repair of teeth with chronic periradicular periodontitis. Int Endod J 1998; 31: 85-89.

20) Leonardo MR, Salgado AA, da Silva LA, Tanomaru Filho M. Apical and periapical repair of dogs' teeth with periapical lesions after endodontic treatment with different root canal sealers. Pesqui Odontol Bras 2003; 17: 69-74.

21) Garcia Lda F, Marques AA, Roselino Lde M, Pires-de-Souza Fde C, Consani S. Biocompatibility evaluation of Epiphany/ Resilon root canal filling system in subcutaneous tissue of rats. J Endod 2010; 36: 110-114.

22) Silva-Herzog D, Ramírez T, Mora J, Pozos AJ, Silva LA, Silva RA, Nelson-Filho P. Preliminary study of the inflammatory response to subcutaneous implantation of three root canal sealers. Int Endod J 2011; 44: 440-446.

23) Mutoh N, Tani-Ishii N. A biocompatible model for evaluation of the responses of rat periapical tissue to a new zinc oxideeugenol sealer. Dent Mater J 2011; 30: 176-182.

24) Hasegawa T, Suzuki H, Yoshie H, Ohshima H. Influence of extended operation time and of occlusal force on determination of pulpal healing pattern in replanted mouse molars. Cell Tissue Res 2007; 329: 259-272.

25) Lee M, Winkler J, Hartwell G, Stewart J, Caine R. Current trends in endodontic practice: emergency treatments and technological armamentarium. J Endod 2009; 35: 35-39.

26) Andreasen JO, Borum MK, Jacobsen HL, Andreasen FM. Replantation of 400 avulsed permanent incisors. 1. Diagnosis of healing comlications. Endod Dent Traumatol 1995; 11: 5158.

27) Ogasawara T, Yoshimine Y, Yamamoto M, Akamine A. Biocompatibility of an experimental glass-ionomer cement sealer in rat mandibular bone. Oral Surg Oral Med Oral Pathol Oral Radiol Endod 2003; 96: 458-465.
28) Olsson B, Sliwkowski A, Langeland K. Intraosseous implantation for biological evaluation of endodontic materials. J Endod 1981; 7: 253-265.

29) Langeland K, Spangberg L. Methodology and criteria in evaluation of dental endosseous implants. J Dent Res 1975; 54: 158-165.

30) Friend LA, Browne RM. Tissue reactions to some root filling materials. Br Dent J 1968; 125: 291-298.

31) Ames JM, Loushine RJ, Babb BR, Bryan TE, Lockwood PE, Sui M, Roberts S, Weller RN, Pashley DH, Tay FR. Contemporary methacrylate resin-based root canal sealers exhibit different degrees of ex vivo cytotoxicity when cured in their self-cured mode. J Endod 2009; 35: 225-228.

32) Bouillaguet S, Wataha JC, Tay FR, Brackett MG, Lockwood $\mathrm{PE}$. Initial in vitro biological response to contemporary endodontic sealers. J Endod 2006; 32: 989-992.

33) Heitman EP, Joyce AP, McPherson JC 3rd, Roberts S, Chuang A. An in vitro evaluation of the growth of human periodontal ligament fibroblasts after exposure to a methacrylate-based endodontic sealer. J Endod 2008; 34: 186-189.

34) Yamanaka Y, Shigetani Y, Yoshiba K, Yoshiba N, Okiji T. Immunohistochemical analysis of subcutaneous tissue reactions to methacrylate resin-based root canal sealers. Int Endod J 2011; 44: 669-675.

35) Imazato S, Tarumi H, Ebi N, Ebisu S. Cytotoxic effects of composite restorations employing self-etching primers or experimental antibacterial primers. J Dent 2000; 28: 61-67.

36) Willershausen I, Callaway A, Briseño B, Willershausen B. In vitro analysis of the cytotoxicity and the antimicrobial effect of four endodontic sealers. Head Face Med 2011: 7; 15-24.

37) Heil J, Reifferscheid G, Waldmann P, Leyhausen G, Geurtsen W. Genotoxicity of dental materials. Mutat Res 1996; 368: 181-194.

38) Leonardo MR, Bezerra da Silva LA, Filho MT, Santana da Silva R. Release of formaldehyde by 4 endodontic sealers. Oral Surg Oral Med Oral Pathol Oral Radiol Endod 1999; 88: 221-225. 